ARTICLE

\title{
Molecular basis of regio- and stereo-specificity in biosynthesis of bacterial heterodimeric diketopiperazines
}

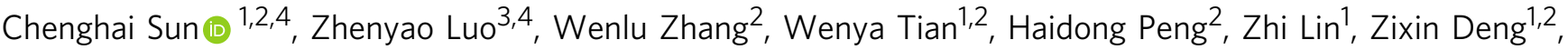 \\ Bostjan Kobe (i) ${ }^{3 凶}$, Xinying Jia (i) ${ }^{3 凶} \&$ Xudong Qu (i) ${ }^{1,2 凶}$
}

Bacterial heterodimeric tryptophan-containing diketopiperazines (HTDKPs) are a growing family of bioactive natural products. They are challenging to prepare by chemical routes due to the polycyclic and densely functionalized backbone. Through functional characterization and investigation, we herein identify a family of three related HTDKP-forming cytochrome P450s (NasbB, Nas 1868 and $\mathrm{Nas}_{\mathrm{F5053}}$ ) and reveal four critical residues (QIn65, Ala86, Ser284 and Val288) that control their regio- and stereo-selectivity to generate diverse dimeric DKP frameworks. Engineering these residues can alter the specificities of the enzymes to produce diverse frameworks. Determining the crystal structures (1.70-1.47 $\AA$ ) of $\mathrm{Nas}_{55053}$ (ligand-free and substrate-bound $\mathrm{Nas}_{55053}$ and its Q65I-A86G and S284A-V288A mutants) and molecular dynamics simulation finally elucidate the specificity-conferring mechanism of these residues. Our results provide a clear molecular and mechanistic basis into this family of HTDKP-forming P450s, laying a solid foundation for rapid access to the molecular diversity of HTDKP frameworks through rational engineering of the P450s.

\footnotetext{
${ }^{1}$ State Key Laboratory of Microbial Metabolism and School of Life Sciences and Biotechnology, Shanghai Jiao Tong University, 200240 Shanghai, China. ${ }^{2}$ Key Laboratory of Combinatorial Biosynthesis and Drug Discovery, Ministry of Education, Wuhan University School of Pharmaceutical Sciences, 430071 Wuhan, China. ${ }^{3}$ School of Chemistry and Molecular Biosciences, Institute for Molecular Bioscience and Australian Infectious Diseases Research Centre, The University of Queensland, St. Lucia, QLD 4072, Australia. ${ }^{4}$ These authors contributed equally: Chenghai Sun, Zhenyao Luo. ${ }^{凶}$ email: b.kobe@uq.edu.au; x.jia1@uq.edu.au; quxd19@sjtu.edu.cn
} 
$\mathrm{N}$ atural products derived from tryptophan-containing diketopiperazine (TDKP) comprise a large class of secondary metabolites ${ }^{1-3}$. Among them, heterodimeric tryptophan-containing diketopiperazines (HTDKPs) are particularly attractive for their unique structural architecture and fascinating bioactive properties, ranging from anticancer, antiplasmodial, anti-HIV, and neuroprotective activities ${ }^{1-6}$. TDKPs are primarily produced by fungal systems, in which two pyrroloindoline units are predominantly fused together by a C3-C3' bond ${ }^{3,7,8}$. Bacterially-sourced HTDKPs are much rarer, but their structural architectures are more versatile ${ }^{4-6,9-11}$. Based on their connectivities and stereochemistry, the dimeric DKP frameworks can be classified into five different types (Fig. 1): (I) C3-C7', 2R$3 \mathrm{~S}$ (e.g., naseseazine $\mathrm{B}$ or NAS-B ${ }^{4,9}$ ); (II) C3-C7', 2S-3R (e.g., NAS-36). (III) C3-C6', 2S-3R (e.g., naseseazine C or NAS-C ${ }^{5}$ ); (IV) C3-C6', 2R-3S (e.g., iso-NAS-B ${ }^{11}$ ); and (V) N1-C7' (e.g., aspergilazine A or Asp- $\mathrm{A}^{10}$ ).

The regio-specificity and stereo-specificity in the densely functionalized frameworks, especially at the quaternary stereocenter at the $\mathrm{C} 3$ position, renders chemical synthesis of bacterial HTDKPs very challenging $9,12-14$. To develop efficient biocatalytic approaches, we recently investigated the biosynthesis of naseseazine $\mathrm{C}$ (NAS-C) and identified a key diketopiperazine (DKP) forming $\mathrm{P} 450$ enzyme $(\mathrm{NascB})^{6}$. NascB catalyzes a radical cascade reaction to form intramolecular and intermolecular carbon-carbon bonds with both regio-specificity and stereospecificity, which is very efficient in constructing the HTDKP frameworks and has been used to create 30 type I-IV NAS analogs employing different DKP substrates ${ }^{6}$. Very recently, Li and coworkers further identified two other P450 enzymes, AspB and $\mathrm{NasB}$, which are responsible for the predominant formation of aspergilazine A (ASP-A) and NAS-B, respectively ${ }^{11}$ (Supplementary Table 1). Unusually, HTDKP-forming P450s have relaxed regio-specificity and stereo-specificity and can generate products with different frameworks, e.g., AspB is able to convert cyclo-L-Trp-L-Pro $\left(\mathrm{cW}_{\mathrm{L}}-\mathrm{P}_{\mathrm{L}}\right)$ into NAS-C (type III) and iso-NAS$\mathrm{B}$ (type IV) accompanying the major product ASP-A (type V) ${ }^{11}$. This property of co-generation of different types of HTDKPs suggests these $\mathrm{P} 450$ s have a regulatory mechanism in controlling different regio-specificities and stereo-specificities and presents a great potential for further improving catalytic efficiency, altering specificity and even creating diverse frameworks by rational protein engineering. However, such endeavors are reliant on understanding the molecular basis of HTDKPs-producing P450catalyzed reactions, which currently remains elusive.

To this end, we herein functionally characterize three HTDKPforming P450s (NasbB, $\mathrm{Nas}_{\mathrm{S} 1868}$, and $\mathrm{Nas}_{\mathrm{F} 5053}$ ), structurally characterize $\mathrm{Nas}_{\mathrm{F} 5053}$ and its mutants by X-ray crystallography, and explore the further catalytic potential of the fourth pertinent $\mathrm{P} 450$ (NascB). Our results reveal that four key residues (Q65, A86, S284, and V288, according to the $\mathrm{Nas}_{\mathrm{F} 5053}$ numbering; PDB ID 6W0S) are crucial for controlling the combination of the different regio-specificities and stereo-specificities. Based on our structural characterization, molecular dynamics and mutagenesisvalidation of the residues involved, we elucidate how the regioconfiguration and stereo-configuration in forming bonds is finely tuned in these P450s.

\section{Results}

Identifying the P450s producing NAS-B and ASP-A. Previously, we identified three distinct loci (locus-1, 2, and 3) in the Streptomyces CMB-MQ030, each of which contained genes encoding one cyclodipeptide synthase (CDPS) and one adjacent P450. The P450 NascB (CYP nomenclature: CYP1190B2) encoded in locus- 1 was responsible for the biosynthesis of NAS- $\mathrm{C}^{6}$. To verify the functionality of locus-2, its $\mathrm{P} 450 \mathrm{NasbB}$ was expressed in the Mycobacterium system. In the presence of spinach flavodoxin (Fd) and flavodoxin reductase (FdR), as well as an NADPH

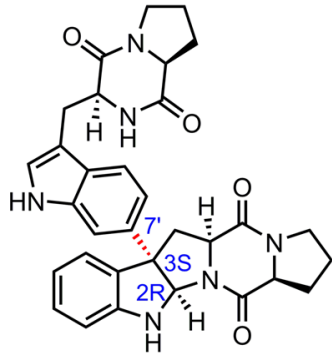

NAS-B

(Type I)

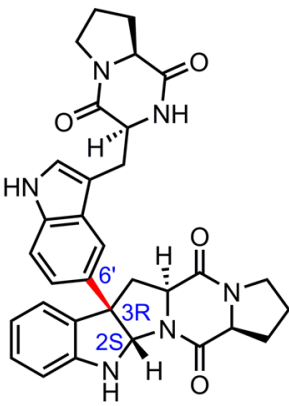

NAS-C

(Type III)

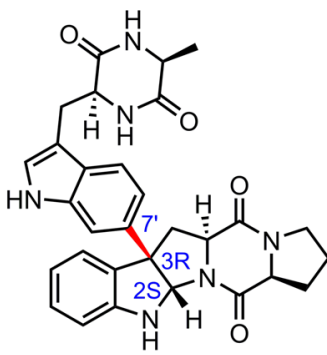

NAS-3

(Type II)

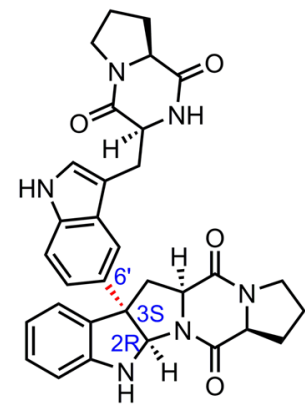

Iso-NAS-B

(Type IV)

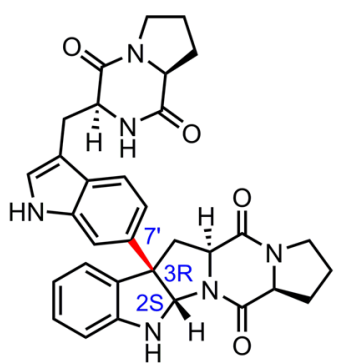

NAS-E (this study)

(Type II)

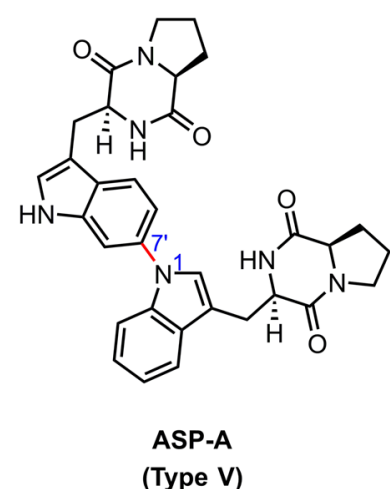

(Type V)

Fig. 1 The structures of representative bacterial HTDKP natural products. The bond connectivity of two DKP moieties (red) and the C2-C3 chirality (blue labels) are highlighted. NAS-E was produced in this study. 
NascB .... PVCPVVSEGTGDPLWLVTRYATAVKLLEDSRFSSEAAQASGAPRQEPVELRAPGTRGDAIAMLREAGLRS

Nas $_{\text {F5053 }} \ldots$... PVCPVVSEGTGDPLWLVTRYATAVKLLEDSRFSSEAAQASGAPRQEPVELRAPGTRGDAIAMLREAGLRS

Nas $_{\mathbf{S 1 8 6 8}}$... PVCPVVSEGTGDHLWLATRYAAAVELLEDPRLSSEAAIASGAPRQEPVELRAPGTRADGVAMLREAGLRS

125

NascB VLADGLGPRAVRRHQKWI HEYAETLIGELVDREGTFDLARE FAEPLSSAVVSRTLLGELTSDERARLVGW . . . . Nas $_{F_{5053}}$ VLADGLGPRAVRRHQGWINDLAETLMSELASREGTFDLAADFVEPLSSALVSRTLLGELSADERDLLAHC . . . . Nas $_{\text {s1868 }}$ VLADGLGPRAVRRHQGW INDLAETLMSALASREGTFDLAADFVEPLSSALVSRTLLGELSADERDLLAHC . . . .

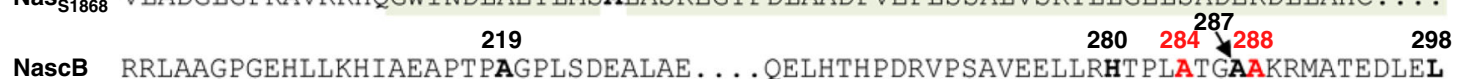
Nas $_{\text {F053 }}$ RRLAGTPGEHLLKLIAEAPVDQGPLSDEALAE . . . . QELHAHPERVPSAVEELLRYTPLSTGSVKRMATEDLEI Nas $_{\mathbf{S 1 8 6 8}}$ RRLAGTPGEHLLKLIAEAPVDHGPLSDEALAE . . . . QELHAHPERVPSAVEELLRYTPLSTGSVKRMATEDLEI 305 $\mathrm{K}$ Fragment-7 $\longrightarrow$ NascB DGVRIGAGEVVMVSFEAVNRDPDAFEDPDRFRPGREGPMHFGFGRGRHTCPGNRLARCLIEATVRAVACH.... Nas $_{\text {F5053 }_{3}}$ DGVRIKAGEVVMVSLEAVNHDPDAFEDPDVFRPGREGPMHFGFGRGRHFCPGNRLARCVIEATVRAVARR.... Nas $_{\mathbf{s 1 8 6 8}}$ DGVRI KVGEVVMVSLEAVNHDPDAFEDPDVFRPGREGPMHFGFGRGRHFCPGNRLARCVIEATVRAVARR . . . .

b

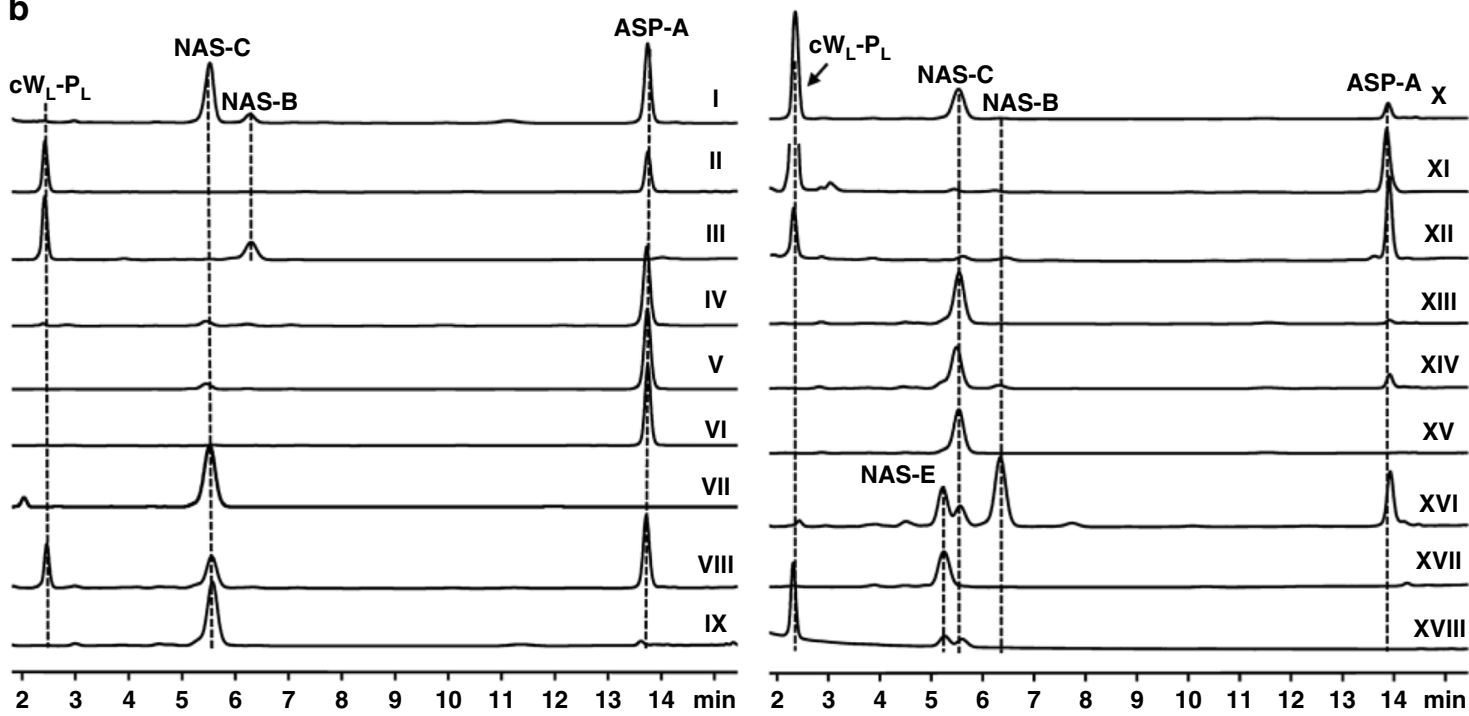

Fig. 2 Deciphering and engineering the regio-specificity and stereo-specificity of HTDKP forming P450s. a The sequence alignments of NascB,

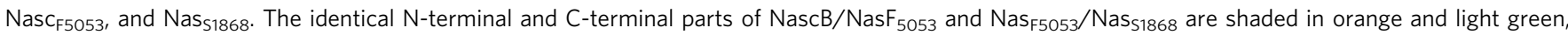
respectively. Residues less important are not shown and indicated by dashed lines. The four critical residues are bolded and highlighted by colors. $\mathbf{b}$ In vitro

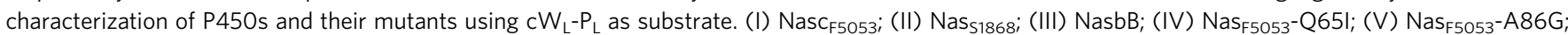

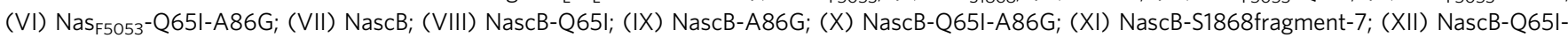

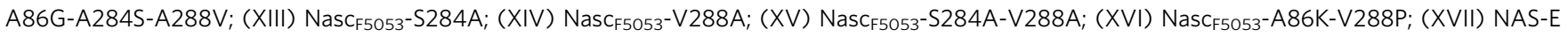

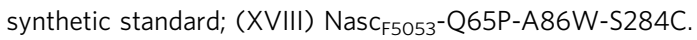

recycling system (NADP, glucose and glucose dehydrogenase), NasbB was confirmed to efficiently dimerize the $\mathrm{cW}_{\mathrm{L}}-\mathrm{P}_{\mathrm{L}}$ into NAS-B (Fig. 2b, trace III; NMR and HRMS data see Supplementary Fig. 1, Supplementary Fig. 2 and Supplementary Table 2). In the meantime, Li et al identified a homologous $\mathrm{P} 450$ (NasB, 96\% identity to NasbB) from Streptomyces NRRL S-1868, also generating NAS- $\mathrm{B}^{11}$.

As the P450 enzymes with highly similar sequences can produce different products, we were interested in establishing the relationship between enzyme sequences and the corresponding products. Although NascB and NasbB share 68\% sequence identity, it is difficult to extract the key residues responsible for the difference in product formation. In order to identify more P450s which could potentially generate some other kinds of C3aryl pyrroloindolines, we used simple sequence searches to find genes homologous to $n a s c B$ or nasbB. We identified two previously uncharacterized $\mathrm{P} 450$ proteins: $\mathrm{Nas}_{\mathrm{F} 5053}$ and $\mathrm{Nas}_{\mathrm{S} 1868}$ from the Streptomyces strain sp. NRRL F-5053 and sp. NRRL S-1868, respectively. Soluble recombinant $\mathrm{Nas}_{\mathrm{F} 5053}$ (CYP nomenclature: CYP1190B1) could be expressed in E. coli BL21 (DE3), while soluble $\mathrm{Nas}_{\mathrm{S}_{1868}}$ (CYP nomenclature: CYP1190B1) could only be expressed in Mycobacterium smegmatis $\mathrm{MC}^{2} 155$.

Using an in vitro assay employing the electron-transport system (Fd and FdR) from spinach, $\mathrm{Nas}_{\mathrm{S} 1868}$ can convert $\mathrm{cW}_{\mathrm{L}}-\mathrm{P}_{\mathrm{L}}$ into Asp-A (Fig. 2b, trace II; NMR and HRMS data see Supplementary Fig. 2, Supplementary Fig. 3 and Supplementary Table 3); a similar observation was also made by $\mathrm{Li}$ et al. ${ }^{11}$ ). Further, the in vitro assay confirmed that $\mathrm{Nas}_{\mathrm{F} 5053}$ could produce NAS-C (47.4\%), Asp-A (44.4\%), as well as a minor product NASB (8.2\%) (Fig. 2b, trace I). This catalysis profile is well correlated with the sequence alignments of $\mathrm{Nas}_{\mathrm{F} 5053}, \mathrm{NascB}, \mathrm{Nas}_{\mathrm{S} 1868}$ and NasbB. Based on the sequence alignments, $\mathrm{Nas}_{\mathrm{F} 5053}$ can be viewed as a chimeric form of NascB and $\mathrm{Nas}_{\mathrm{S} 1868}$. The first 112 residues of $\mathrm{Nas}_{\mathrm{F} 5053}$ are exactly the same as NascB (Fig. 2a). Except for mismatches in residues 125, 219, and 305, the C-terminal 273 residues of $\mathrm{Nas}_{\mathrm{S}_{1868}}$ and $\mathrm{Nas}_{\mathrm{F5053}}$ are identical (Fig. 2a). This simple protein chimera strongly implies that the N-terminal portion of $\mathrm{Nas}_{\mathrm{F} 5053}$ contains residues that are involved in the 
generation of NAS-C, while the C-terminal part of $\mathrm{Nas}_{\mathrm{F} 5053}$ harbors residues that are involved in the generation of ASP-A. Therefore, $\mathrm{Nas}_{\mathrm{F} 5053}, \mathrm{NascB}$, and $\mathrm{Nas}_{\mathrm{S} 1868}$ provide a suitable portfolio of $\mathrm{P} 450$ to reveal the relationships between enzyme sequences and the corresponding products.

Identifying the keys residues which determine the regioconfiguration and stereo-configuration. Next, to identify the roles of critical residues in regulating and controlling the product profiles of the $\mathrm{P} 450$ enzymes, a series of protein variants was generated with mutations in the $\mathrm{N}$-terminal and $\mathrm{C}$-terminal portions of $\mathrm{Nas}_{\mathrm{F} 5053}$ and $\mathrm{NascB}$, and the resultant mutant proteins were tested by enzyme assays. In the $\mathrm{N}$-terminal part of $\mathrm{Nas}_{\mathrm{F5053}}$, we converted the following residues to their corresponding amino-acids in $\mathrm{Nas}_{\mathrm{S} 1868}$ : V44A-T49A-K52E (triple mutant), and $\mathrm{P} 40 \mathrm{H}, \mathrm{Q} 65 \mathrm{I}, \mathrm{G} 84 \mathrm{~A}, \mathrm{~A} 86 \mathrm{G}$, and $\mathrm{I} 87 \mathrm{~V}$ (point mutants). The in vitro enzyme assays of the $\mathrm{Nas}_{\mathrm{F} 5053}$ mutants $\left(\mathrm{P} 40 \mathrm{H}\right.$ could not be tested as it was insoluble) using $c W_{\mathrm{L}}-\mathrm{P}_{\mathrm{L}}$ showed that the simultaneous mutation of V44A, T49A, and K52E and single mutation of G84A or I87V imposed a slight change to the ratio of NAS-C and ASP-A (Supplementary Fig. 4, trace I-IV). Similarly, none of the eight point-mutations $(\mathrm{P} 40 \mathrm{H}$, V44A, T49A, K52E, S57P, F59L, G84A, and I87V) in the Nterminal portion of $\mathrm{NascB}$ were able to engineer $\mathrm{NascB}$ to produce ASP-A (Supplementary Fig. 4, trace V-XII). These eight positions were thus not investigated further. On the other hand, the single mutations Q65I and A86G in $\mathrm{Nas}_{\mathrm{F} 5053}$ dramatically reduced the production of NAS-C (Fig. 2b, trace IV, V). Furthermore, the double mutation A86G-Q65I almost abolished the production of NAS-C, leaving ASP-A as the only detectable product (Fig. 2b, trace VI). These results clearly indicate that Q65 and A86 are the two crucial residues in $\mathrm{Nas}_{\mathrm{F} 5053}$ that that direct the enzyme to produce NAS-C.

In the following steps, the same mutations (Q65I and A86G) were introduced into NascB. The Q65I mutation in NascB also impacted on the production of NAS-C; it decreased the production of NAS-C and increased the production of ASP-A from none to reach the NAS-C to ASP-A ratio of 5:7 (Fig. 2b, trace VIII). The single mutation $\mathrm{A} 86 \mathrm{G}$ in $\mathrm{NascB}$ had a negligible effect on the production of ASP-A, whereas it neutralized the effect of Q65I in the A86G-Q65I double mutant, which is opposite to the synergistic effect observed in $\mathrm{Nas}_{\mathrm{F5053}}$ (Fig. 2b, trace IX, X). The contrasting effect of Q65 and A86 in NascB, as compared to $\mathrm{Nas}_{\mathrm{F} 5053}$, prompts us to hypothesize that more residues in the $\mathrm{C}$-terminal portion of NascB contribute to regulating the production of NAS-C and ASP-A. Because the Cterminal portion of $\mathrm{NascB}$ exhibits significant sequence differences, compared to $\mathrm{Nas}_{\mathrm{S} 1868}$, the C-terminal part of $\mathrm{NascB}$ was divided into eight fragments (Supplementary Fig. 5). Each of the eight fragments was then replaced by the corresponding fragment in Nas $\mathrm{N}_{1868}$, with Q65I and A86G mutations already in place. Each of eight NascB mutants was purified and enzyme assays revealed that the seventh fragment (fragment-7, carrying five mutations: H280Y, A284S, A287S, A288V, and L298I) almost abolished the production of NAS-C and generated ASP-A as the sole product (Fig. 2b, trace XI and Supplementary Fig. 6).

Point mutants were made to identify the effect of every single mutation in fragment-7 on the product profile. All five single point mutations produced more NAS-C than ASP-A (Supplementary Fig. 7, trace I-V), indicating more than one-substitution in fragment-7 is required to make ASP-A as the predominant product. We therefore restored, one by one, each of five-point mutations in the fragment-7 to its wild-type amino-acid of $\mathrm{NascB}$, and observed that $\mathrm{S} 284 \mathrm{~A}$ or V288A counteracted the overall effect of five-point mutations in fragment-7 most
(Supplementary Fig. 7, trace VI-X). The results suggest that S284 and V288 are the two critical residues for the generation of ASP-A, while A284 and A288 are essential for the generation of NAS-C. Finally, the combination of Q65I-A86G-A284S-A288V in the NascB quadruple mutant was confirmed to make ASP-A as the major product (Fig. $2 \mathrm{~b}$, trace XII). In the case of $\mathrm{Nas}_{\mathrm{F} 5053}$, the single mutations $\mathrm{S} 284 \mathrm{~A}$ or V288A significantly reduced the production of ASP-A, while the production of NAS-C was unaffected; and the double mutation S284A-V288A almost completely abolished the production of ASP-A (Fig. 2b, trace XIII-XV), hence unequivocally confirming the crucial role for these residues in determining the selective production of ASP-A and NAS-C. In addition to impact on the production of ASP-A and NAS-C, we also observed a reduced production of NAS-B in $\mathrm{Nas}_{\mathrm{F} 5053}-\mathrm{Q} 65 \mathrm{I}, \mathrm{Nas}_{\mathrm{F5053}}-\mathrm{A} 86 \mathrm{G}$, and $\mathrm{Nas}_{\mathrm{F} 5053}-\mathrm{S} 284 \mathrm{~A}$ (Fig. 2b, trace IV, V, XIII). Therefore, these residues in the four positions of $65,86,284,288$ apparently play the determining role in controlling regio-specificity and stereo-specificity of the generation of different frameworks in bacterial HDTKPs.

Saturation mutagenesis of key residues to create different regio-specificities and stereo-specificities. Considering that the reaction specificity of $\mathrm{P} 450$ s can be regulated by only four key residues, we hypothesized that the creation of other frameworks with different regio-selectivities and stereo-selectivities is possible through engineering these four sites. Thus, the four key residues in $\mathrm{Nas}_{\mathrm{F} 5053}$ (Q65, A86, S284, V288) were chosen simultaneously for NNK-based saturation mutagenesis. The mutated plasmids were transferred into GBdir-T7 E. coli containing spinach Fd and FdR, a whole-cell biocatalysis system we developed previously ${ }^{6}$. A small library of four hundred colonies was selected and assayed using $\mathrm{cW}_{\mathrm{L}}-\mathrm{P}_{\mathrm{L}}$ as a substrate. As expected, the production of NAS$\mathrm{B}$ was significantly improved in some mutants. Among them, the mutant $\mathrm{Nas}_{\mathrm{F5053}}-\mathrm{A} 86 \mathrm{~K}-\mathrm{V} 288 \mathrm{P}$ not only yielded the highest ratio of NAS-B/ NAS-C (Fig. 2b, trace XVI, and Supplementary Fig. 8) but also produced another HTDKP product. Interestingly, $\mathrm{Nas}_{\mathrm{F5053}}$-Q65P-A86W-S284C also produced such compound, instead of NAS-B, in a ratio of $6: 4$ relative to NAS-C (Fig. $2 b$, trace XVIII). NMR and MS analyses identified this product, here we named as NAS-E; it contains a C3-aryl pyrroloindoline framework with a C3-C7' linkage and 2S-3R stereo-configuration (the type II HTDKP) (Fig. 1; NMR and HRMS data see Supplementary Fig. 9, Supplementary Fig. 2 and Supplementary Table 4). In order to validate this structure, we also synthesized it according to the reported total chemical synthesis strategies ${ }^{14}$, and the comparison of the HPLC and NMR data of the synthetic compound with NAS-E unequivocally confirmed our proposed NAS-E structure (Fig. 2b, trace XVII and Supplementary Fig. 10). Cumulatively, both the production of NAS-E and the significant improvement in the yield of NAS-B further provide a compelling evidence that the four identified key residues control the regiospecificity and stereo-specificity of $\mathrm{Nas}_{\mathrm{F} 5053}$ catalyzed-reactions.

Crystal structures of NasF5053 and re-engineered mutants in complex with substrates. To further understand the molecular basis of product diversity of $\mathrm{Nas}_{\mathrm{F} 5053}$ and its homologs, we determined high-resolution structures of wild-type $\mathrm{Nas}_{\mathrm{F} 5053}$ in its substrate-free (PDB ID 6W0S, Supplementary Fig. 11) and substrate-bound (PDB ID 6VXV) forms (Fig. 3a), by X-ray crystallography (Supplementary Table 5). $\mathrm{Nas}_{\mathrm{F} 5053}$ adopts the prism-like fold characteristic for P450s, consisting of a large domain of 10-helices (C-L) and a small domain of four $\alpha$-helices (A, B, B', and $\mathrm{K}^{\prime}$ ) and three $\beta$-sheets (strands $\beta 1-1$ to $4, \beta 2-1$ to 2 , and $\beta 3-1$ to 2 ) (Supplementary Fig. 11). The prosthetic heme group is bound at the crevice formed between helices I and L. Its 

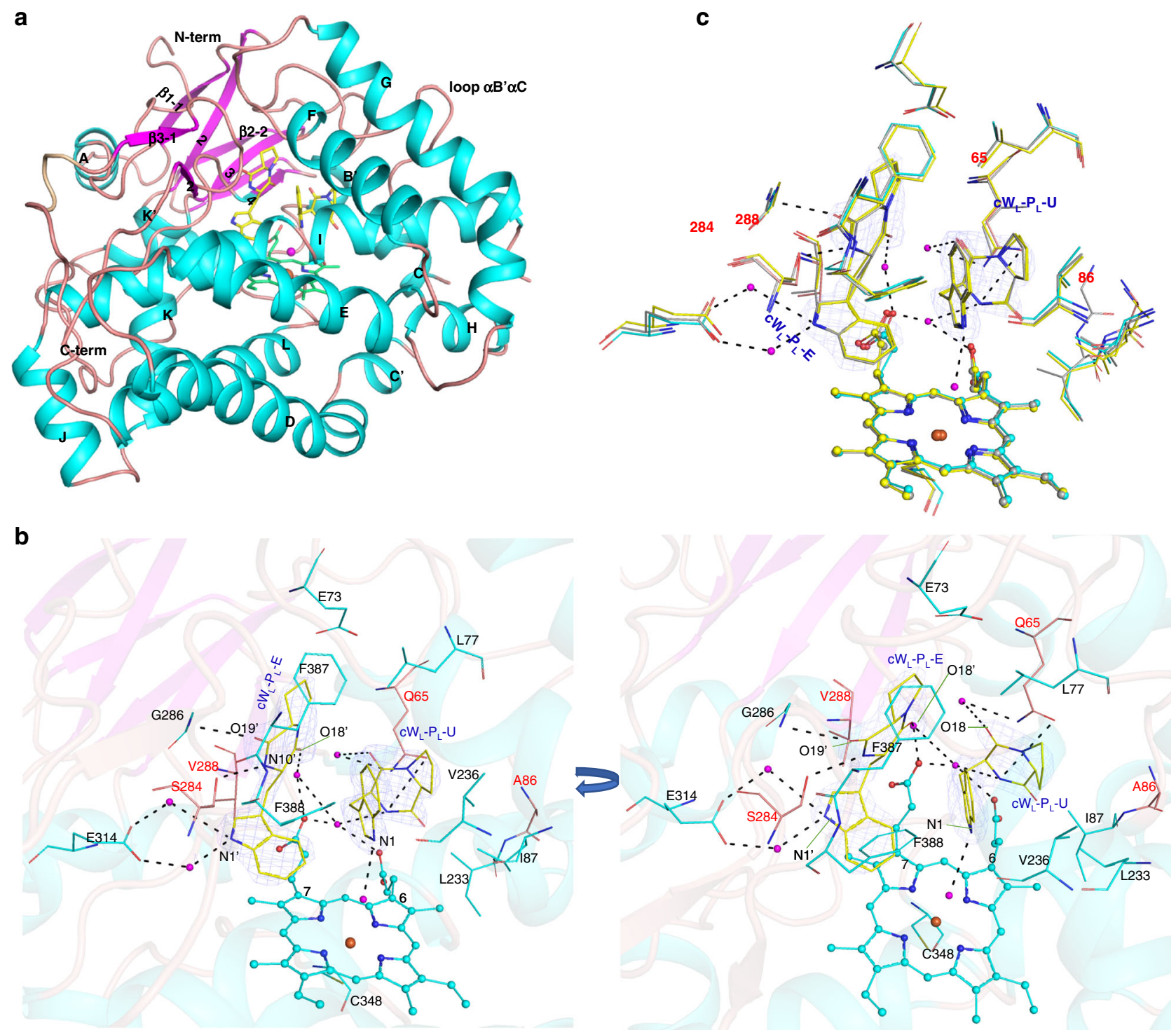

Fig. 3 Crystal structures of $\mathbf{N a s}_{\mathbf{F 5 0 5 3}}$ and its mutants. a Cartoon representation of the structure of $\mathrm{Nas}_{\mathrm{F} 5053}$ bound to $\mathrm{cW} \mathrm{W}_{\mathrm{L}}-\mathrm{P}_{\mathrm{L}}$. Elements of secondary structure and the $\mathrm{N} / \mathrm{C}$-termini are labeled; $\alpha$-helices are shown in cyan and $\beta$-strands in magenta. The iron in the heme is shown as a brown sphere and water molecules are displayed as magenta spheres. Other parts of the heme and $c W_{L}-P_{L}$ are displayed as green and yellow sticks, respectively. $\mathbf{b} A$ representation of the active site of $\mathrm{Nas}_{\mathrm{F} 5053}$ in complex with $\mathrm{cW}_{\mathrm{L}}-\mathrm{P}_{\mathrm{L}}-\mathrm{E}$ and $\mathrm{cW} \mathrm{L}-\mathrm{P}_{\mathrm{L}}-\mathrm{U}$ shown as yellow sticks. Oxygen and nitrogen atoms are shown in red and blue, respectively. The heme is displayed in cyan ball-and-stick representation, with the iron presented as a brown sphere. Nas 55053 residues are colored in cyan. Left: "side" view of the active site; right, "top" view. Probable H-bonds between Nas F5053, $\mathrm{CW}_{\mathrm{L}}-\mathrm{P}_{\mathrm{L}}$, heme propionate and water molecules (magenta spheres) are indicated as dotted lines. Four critical residues (Q65, A86, S284, and V288) are highlighted in red and shown as orange

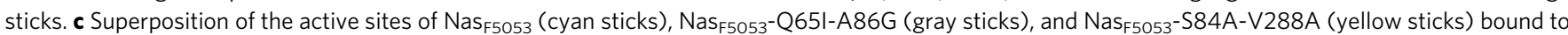
$c W_{L}-P_{L}-E$ and $c W_{L}-P_{L}-U$. The locations of four critical residues $(65,86,284$, and 288) are highlighted. The three complex structures are nearly identical, except for the mutated and adjacent residues. The $c W_{\mathrm{L}}-\mathrm{P}_{\mathrm{L}}-\mathrm{E}$ and $\mathrm{cW}_{\mathrm{L}}-\mathrm{P}_{\mathrm{L}}-\mathrm{U}$ substrates in the NasF5053 complex structure are surrounded by Fo-Fc electron density omit map, which is calculated after 20 cycles of refinement in the absence of the ligands and contoured at $2.0 \sigma$ level (blue mesh).

heme iron is coordinated by the axial ligand Cys348 in helix L. At the distal side of the heme, the iron is coordinated by a water molecule (Supplementary Fig. 11), consistent with the EPR data for $\mathrm{NascB}^{6}$ and $\mathrm{CYP} 121^{15}$ that water is coordinated predominantly to low-spin Fe (III).

Comparison between the substrate-free and substrate-bound $\mathrm{Nas}_{\text {F5053 }}$ structures reveals binding of substrates only invokes minimal conformational changes, with a root-mean-square deviation (RMSD) of $0.362 \AA$ (for $388 \mathrm{Ca}$ atoms) between the two forms (Supplementary Fig. 12). Instead, substrate binding is associated with rearrangements of some of the residues lining the substrate-binding cavity. Upon substrate binding, the side-chains of both D85 and E73 rotate along the Ca-C $\beta$ axis away from the binding site, to accommodate the substrates. Q65 undergoes a 2.0 $\AA$ shift (measured on the $\mathrm{C} \delta$ atom) toward the binding site, to interact with one of the substrate molecules $\left(\mathrm{cW}_{\mathrm{L}}-\mathrm{P}_{\mathrm{L}}-\mathrm{U}\right.$; see below). Notably, Q65, D85, and E73 all reside in the long $\alpha B^{\prime}$ aC loop.

In the substrate-bound $\mathrm{Nas}_{\mathrm{F} 5053}$ structure, two $\mathrm{cW}_{\mathrm{L}}-\mathrm{P}_{\mathrm{L}}$ molecules $\left(\mathrm{cW}_{\mathrm{L}}-\mathrm{P}_{\mathrm{L}}-\mathrm{E}\right.$ and $c \mathrm{~W}_{\mathrm{L}}-\mathrm{P}_{\mathrm{L}}-\mathrm{U} ; \mathrm{E}$ and $\mathrm{U}$ indicate extended and $\mathrm{U}$-shaped, respectively) are present in the binding site, with full occupancy. $c W_{L}-P_{L}-E$ adopts an extended conformation and forms multiple contacts with the heme group, loop $\beta 3-1-\beta 3-2$, loop $\alpha B^{\prime}-\alpha C$, and loop $\alpha \mathrm{K}-\beta 1-4$. F387 and L77 form hydrophobic 
interactions with the proline portion of extended $c W_{L}-P_{L}-E$. Formation of hydrogen bonds is observed between S284 and the backbone amide nitrogen of G286, with N10' and O19' of the substrate, respectively. $\mathrm{O} 18$ ' and $\mathrm{N} 1$ ' are indirectly in contact with 7-propionate of the heme and E314, respectively, mediated via hydrogen bonding with water molecules. The hydrophobic side of V288 also protrudes towards 7-propionate of the heme and indole ring in $\mathrm{cW}_{\mathrm{L}}-\mathrm{P}_{\mathrm{L}}-\mathrm{E}$ (Fig. 3b).

On the other side, $c W_{L}-P_{L}-U$ is mainly in contact with the heme, $\alpha \mathrm{I}, \alpha \mathrm{B}^{\prime}$ and long loop $\alpha \mathrm{B}^{\prime}-\alpha \mathrm{C}$, including a T-shaped stacking interaction network between the F388 side-chain and the indole rings of both $\mathrm{cW}_{\mathrm{L}}-\mathrm{P}_{\mathrm{L}}-\mathrm{E}$ and $\mathrm{cW}_{\mathrm{L}}-\mathrm{P}_{\mathrm{L}}-\mathrm{U}$. The DKP ring of $\mathrm{cW}_{\mathrm{L}}-\mathrm{P}_{\mathrm{L}}-\mathrm{U}$ is further restrained by the side-chain of $\mathrm{Q} 65$ and extensively stabilized by secondary interactions with water, 6propionate of the heme, N10, O19, O18, the side-chain amide of Q65 and the backbone $\mathrm{NH}$ of A86. Multiple hydrophobic interactions are also observed with residues lining the binding site, including V236, L233, I87, and Q65. These interactions therefore force $\mathrm{cW}_{\mathrm{L}}-\mathrm{P}_{\mathrm{L}}-\mathrm{U}$ into a $\mathrm{U}$-shaped folded conformation, bringing the indole and prolyl entities into close proximity (Fig. 3b). Notably, the folded conformation of $\mathrm{cW}_{\mathrm{L}}-\mathrm{P}_{\mathrm{L}}-\mathrm{U}$ brings its $\mathrm{C} 2$ and $\mathrm{N} 10$ into close contact ( $3.2 \AA$ distance), making the intramolecular cyclization between $\mathrm{W}_{\mathrm{L}}$ and $\mathrm{P}_{\mathrm{L}}$ in $c \mathrm{~W}_{\mathrm{L}}-\mathrm{P}_{\mathrm{L}}-\mathrm{U}$ possible. Importantly, the indole ring of $c W_{L}-P_{L}-U$ is positioned perpendicular to the heme group plane, with $\mathrm{N} 1$ forming a hydrogen bond with the heme-ligating water molecule (Fig. 3b), consistent with the initial step of $\mathrm{N}$-deprotonation reaction by $\mathrm{P} 450$ compound $\mathrm{I}^{6}$. The indole rings from the two substrate molecules also form a $\mathrm{T}$-shaped stacking interaction with each other. Hence, the complex structure between $\mathrm{Nas}_{\mathrm{F5053}}$ and its substrate reveals a sophisticated orchestrated enzymatic environment where the heme, two identical substrates but different conformations, and the residues lining the substrate-binding cavity, are intimately interwoven.

However, our wild-type $\mathrm{Nas}_{\mathrm{F} 5053}$ crystal structures in complex with $c W_{L}-P_{L}$ could not explain how $\mathrm{Nas}_{\mathrm{F} 5053}$ produced two different products: NAS-C and ASP-A. To explain product selectivity, we therefore determined two more $c W_{L}-P_{L}$ substratebound crystal structures, of the mutants $\mathrm{Nas}_{55053}-\mathrm{Q} 65 \mathrm{I}-\mathrm{A} 86 \mathrm{G}$ (PDB ID 6VZA) and $\mathrm{Nas}_{\mathrm{F} 5053}$-S284A-V288A (PDB ID 6VZB). Comparisons among the three substrate-bound structures showed that all substrate-interacting residues, the heme, and the two substrates superimpose well (RMSD in this region between any two structures $<0.26 \AA$; Fig. $3 \mathrm{c}$ ), except for the mutated residues and the adjacent residues such as K289 and I87. These identical crystal structures indicates a common starting conformation for the reactions. To characterize NasF5053-catalyzed reactions further, we performed UV-Vis spectroscopic analysis and molecular dynamics (MD) simulations, to delineate the mechanism of regio-, stereo-selectivity and product profile regulation in NasF5053 and its re-engineered variants.

Spectroscopic characterization of $\mathrm{cW}_{\mathrm{L}}-\mathrm{P}_{\mathrm{L}}$ binding to $\mathrm{Nas}_{\mathrm{F5053}}$. We measure UV-Vis absorption and difference spectra to probe the interaction in solution between $\mathrm{cW}_{\mathrm{L}}-\mathrm{P}_{\mathrm{L}}$ and each of three enzyme variants, i.e., $\mathrm{Nas}_{\mathrm{F5053}}, \mathrm{Nas}_{\mathrm{F} 5053}-\mathrm{Q} 65 \mathrm{I}-\mathrm{A} 86 \mathrm{G}$, and $\mathrm{Nas}_{\mathrm{F} 5053}-\mathrm{S} 284 \mathrm{~A}-\mathrm{V} 288 \mathrm{~A}$. Binding of $\mathrm{cW}_{\mathrm{L}}-\mathrm{P}_{\mathrm{L}}$ to $\mathrm{Nas}_{\mathrm{F} 5053}$ and its double mutants are all shifting a major Soret band from $418 \mathrm{~nm}$ to $387 \mathrm{~nm}$, associating with the transition of the heme iron from the low spin (LS) to high spin (HS) state ${ }^{16}$. This transition, however, is not complete because a small but significant fraction of LS signal still remains even in the saturating $\mathrm{cW}_{\mathrm{L}}-\mathrm{P}_{\mathrm{L}}$ concentration (Supplementary Fig. 13).

Then the difference spectra are used to calculate the spectral variations with OriginPro software. The plotting of the spectral variation as a function of $c W_{L}-P_{L}$ concentration is fitting to a rectangular hyperbola curve, yielding a binding constant of 11.6 $\pm 2.1 \mu \mathrm{M}$ for the interaction between $c W_{\mathrm{L}}-\mathrm{P}_{\mathrm{L}}$ and wild-type $\mathrm{Nas}_{\mathrm{F} 5053}, 25.6 \pm 1.0 \mu \mathrm{M}$ for $\mathrm{cW}_{\mathrm{L}}-\mathrm{P}_{\mathrm{L}}$ with $\mathrm{Nas}_{\mathrm{F} 5053}-\mathrm{Q} 65 \mathrm{I}-\mathrm{A} 86 \mathrm{G}$ and $4.81 \pm 0.26 \mu \mathrm{M}$ for $\mathrm{cW}_{\mathrm{L}}-\mathrm{P}_{\mathrm{L}}$ with $\mathrm{Nas}_{\mathrm{F} 5053}-\mathrm{S} 284 \mathrm{~A}-\mathrm{V} 288 \mathrm{~A}$ (Supplementary Fig. 13). Data fitting to a rectangular hyperbolic shape also models the case of CYP121 with single substrate ${ }^{15}$, suggesting that two $\mathrm{cW}_{\mathrm{L}}-\mathrm{P}_{\mathrm{L}}$ substrates with $\mathrm{Nas}_{\mathrm{F} 5053}$ lack cooperativity for binding and catalysis. This assertion is further supported by a two-ligands complex structure where $c W_{L}-P_{L}$ occupies one site and $c W_{L}-P_{L}$ occupies the other site, which is reported in a published on-line research paper ${ }^{17}$ when we are revising our manuscript.

Molecular dynamics analysis. To characterize $\mathrm{Nas}_{\mathrm{F} 5053}$-catalyzed reactions further, we performed molecular dynamics (MD) simulations with Amber (Supplementary Fig. 14), to delineate the mechanism of regio-selectivity, stereo-selectivity, and product profile regulation in $\mathrm{Nas}_{\mathrm{F} 5053}$ and its re-engineered variants. $\mathrm{MD}$ simulations were performed particularly to analyze the conformational changes associated with the proposed $c W_{L}-P_{L}-U$ radical (Int1, Fig. 4) at the compound II stage ${ }^{6}$. The Q65-A86 and S284-V288 patches orchestrate the regio-specificities and stereospecificities by distinct mechanisms. The Q65-A86 patch is involved in regulating the motion of the long loop $\alpha \mathrm{B}^{\prime}-\alpha \mathrm{C}$, where $\mathrm{Q} 65$ and $\mathrm{A} 86$ reside at its two ends. The conformation of the $\mathrm{aB}$ '$\mathrm{aC}$ loop influences the conformation of the $c W_{\mathrm{L}}-\mathrm{P}_{\mathrm{L}}-\mathrm{U}$ radical. Based on the MD of native $\mathrm{Nas}_{\mathrm{F} 5053}$, the $\mathrm{cW}_{\mathrm{L}}-\mathrm{P}_{\mathrm{L}}-\mathrm{U}$ radical rotates anticlockwise along the axis of N1-Fe (IV)-OH, until two indole rings of the two substrates are almost in a plane. The Q65I and A86G mutations result in a shift of the $\alpha B^{\prime}-\alpha C$ loop away from $\mathrm{cW}_{\mathrm{L}}-\mathrm{P}_{\mathrm{L}}-\mathrm{U}$ radical (Fig. 4a). The consequent relaxation of the restraints on Int1 unfolds Int1 (the distance between N10 and C2 is approximately $4.7 \AA$ in most distance distributions; Fig. $4 \mathrm{~d}$ ). The results exclude the intramolecular cyclization of the $\mathrm{cW}_{\mathrm{L}}-\mathrm{P}_{\mathrm{L}}-$ $\mathrm{U}$ radical to form a pyrroloindoline, without affecting the formation of ASP-A; this observation is consistent with our data that $\mathrm{Nas}_{\mathrm{F5053}}$-Q65I-A86G exclusively produce Asp-A.

The mutations of S284-V288 regulate regio-selectivity and stereo-selectivity by adjusting the relative positions of the two substrates and their conformations. Given that S284 and V288 contribute to lining the binding pocket for $c W_{L}-P_{L}-E$, mutations to less bulky Ala residues create space for $\mathrm{cW}_{\mathrm{L}}-\mathrm{P}_{\mathrm{L}}-\mathrm{E}$ to move towards the heme. This movement disturbs the interactions with the $c W_{\mathrm{L}}-\mathrm{P}_{\mathrm{L}}-\mathrm{U}$ radical, and in turn pushes away the DKP and propyl rings of $c W_{L}-P_{L}-U$ towards $\alpha \mathrm{I}$ (orange sticks in Fig. 4b). This movement rigidifies the DKP ring of the $c W_{L}-P_{L}-U$ radical as evidenced by decreased root-mean-square fluctuations (RMSFs) (Fig. 4f). According to $\mathrm{MD}$, a positive C2-C3-C12N10 dihedral angle between positions N10 above C2 (i.e., N10 attacks the Re face of the indole ring), generating an intermediate that leads to NAS-B, while a negative dihedral angles leaves N10 beneath $\mathrm{C} 2$ (i.e., N10 attacks the $\mathrm{Si}$ face of the indole ring), producing a different intermediate that leads to NAS-C. In the native form, there is a $\sim 4-5$ times higher probability for this dihedral angle to be negative (leading to NAS-C) than positive (leading to NAS-B), which is consistent with the experimental data that $\mathrm{Nas}_{\mathrm{F} 5053}$ produces more NAS-C than NAS-B. The dihedral angle can only be negative in the S284-V288 mutant, echoing that this double mutant can catalyze the formation of only NAS-C (Fig. 4e). MD also shows that the probability of the C2-N10 distance in the wild-type protein being $>4 \AA$ or $<4 \AA$ is almost equal, which means that native $\mathrm{Nas}_{\mathrm{F} 5053}$ could catalyze the formation of the products either requiring or escaping intramolecular cyclization. In the S284-V288 mutant, however, this 


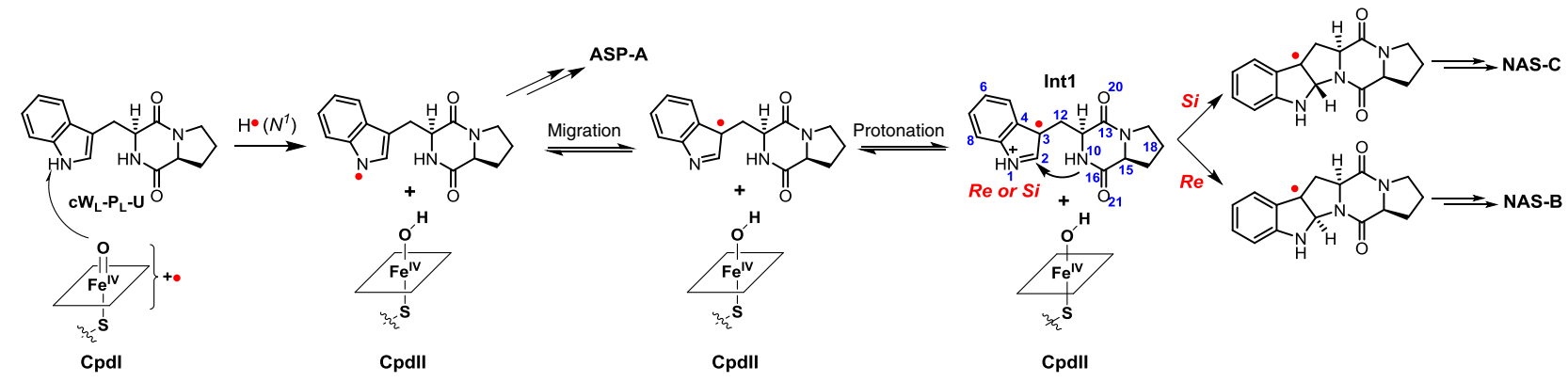

a

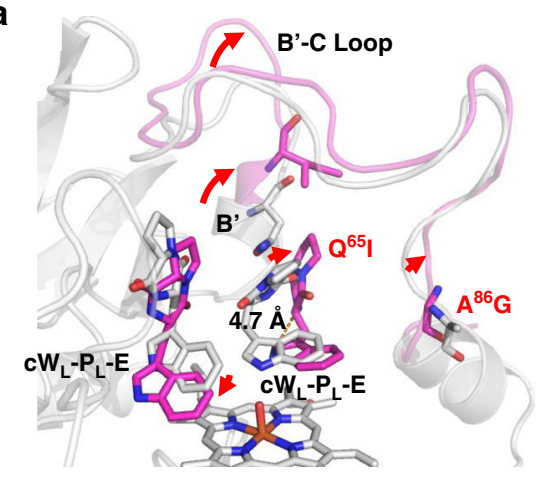

b

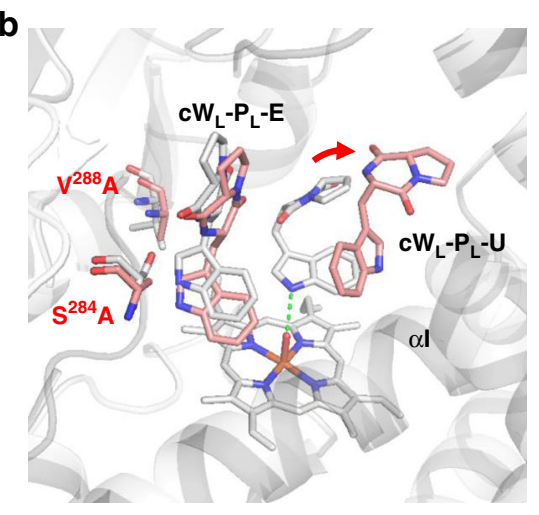

C

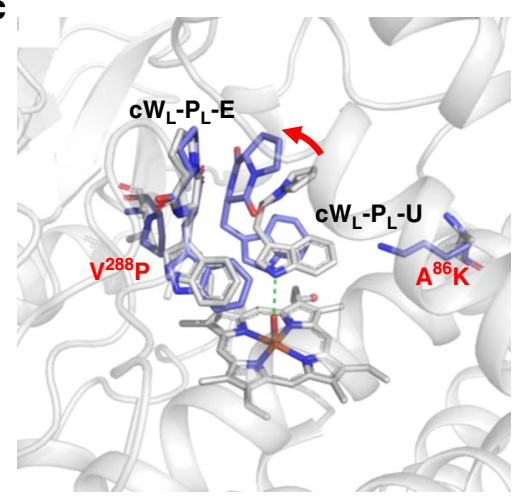

d

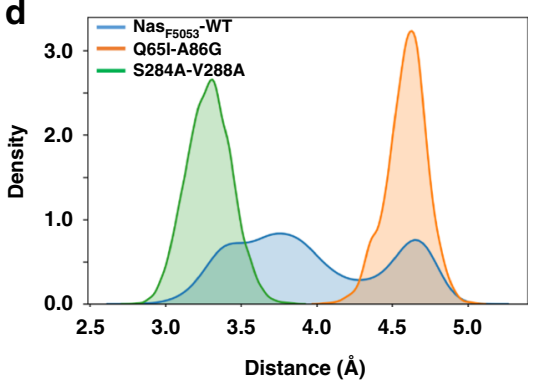

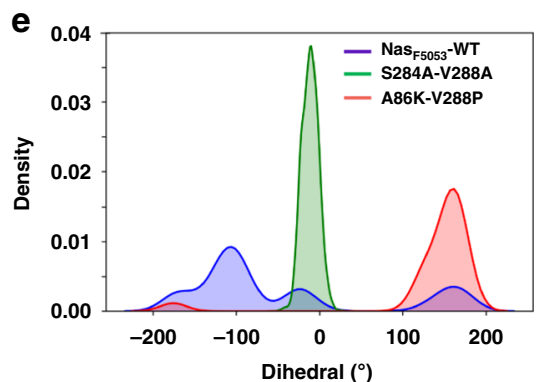

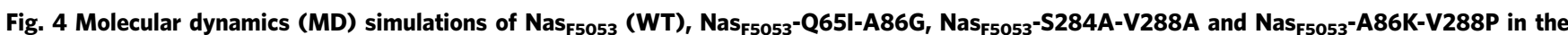
presence of the substrate $\mathbf{c W L}-\mathbf{P}_{\mathbf{L}}-\mathbf{E}$ and the $\mathbf{C W}_{\mathbf{L}}-\mathbf{P}_{\mathbf{L}}-\mathbf{U}$ radical (Int1). Cpdl and CpdII are compound I and compound II, respectively. In a cartoon representation, selected active site residues are shown as sticks. a Superposition of WT Nas 55053 (gray) and Nas F5053-Q65I-A86G (pink). b Superposition

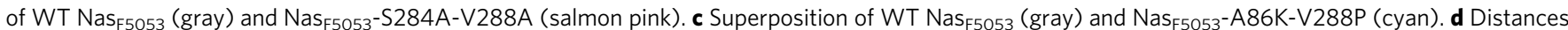
between $\mathrm{N}^{10}$ and $\mathrm{C}^{2}$ of the $\mathrm{CW}_{\mathrm{L}}-\mathrm{P}_{\mathrm{L}}-\mathrm{U}$ radical in WT Nas $\mathrm{F}_{5053}$ (blue), Nas $\mathrm{F}_{5053}-\mathrm{Q} 65 \mathrm{I}-\mathrm{A} 86 \mathrm{G}$ (orange), and Nas $\mathrm{F}_{5053}-\mathrm{S} 284 \mathrm{~A}-\mathrm{V} 288 \mathrm{~A}$ (green).

e $C^{2}-C^{3}-C^{12}-N^{10}$ dihedral angles of the $\mathrm{CW}_{\mathrm{L}}-\mathrm{P}_{\mathrm{L}}-\mathrm{U}$ radical in WT Nas $\mathrm{F}_{5053}$ (blue), Nas $\mathrm{N}_{5053}-\mathrm{S} 284 \mathrm{~A}-\mathrm{V} 288 \mathrm{~A}$ (green), and Nas $\mathrm{N}_{\mathrm{F} 053}-\mathrm{A} 86 \mathrm{~K}-\mathrm{V} 288 \mathrm{P}$ (red). $\mathbf{f}$

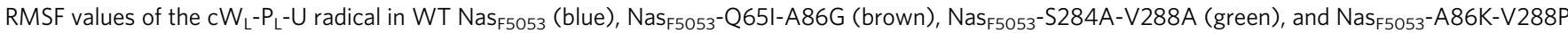
(red). For atom numbers, see the $\mathrm{CW}_{\mathrm{L}}-\mathrm{P}_{\mathrm{L}}-\mathrm{U}$ radical (int1) in the top panel.

distance is fixed between 3.0 and $3.5 \AA$, making intramolecular cyclization inevitable (Fig. 4d).

The re-positioning and conformational changes of the substrates can also be achieved by the combined mutations in both the Q65-A86 and S284-V288 sites, such as the A86K-V288P double mutant. Opposite to its wild-type form, the A86K-V288P mutant produces NAS-B as the major product and NAS-C as the minor product. The long side-chain of K86 protrudes towards $\mathrm{cW}_{\mathrm{L}}-\mathrm{P}_{\mathrm{L}}-\mathrm{U}$ radical and drives its rotation and shift towards $\mathrm{cW}_{\mathrm{L}^{-}}$ $\mathrm{P}_{\mathrm{L}}$-E. On the other side, the V288P mutation compresses the active site, slightly pushing and rotating $\mathrm{cW}_{\mathrm{L}}-\mathrm{P}_{\mathrm{L}}-\mathrm{E}$ (cyan sticks in Fig. 4c). The dual changes of $c W_{\mathrm{L}}-\mathrm{P}_{\mathrm{L}}-\mathrm{U}$ radical and $c \mathrm{~W}_{\mathrm{L}}-\mathrm{P}_{\mathrm{L}}-\mathrm{E}$ reach a conformation where the DKP ring of $\mathrm{cW}_{\mathrm{L}}-\mathrm{P}_{\mathrm{L}}-\mathrm{U}$ radical becomes more rigid. In such a conformation, the $\mathrm{C} 2-\mathrm{C} 3-\mathrm{C} 12-\mathrm{N} 10$ dihedral angle is positive with high probability, favoring the attack of N10 to the Re face of the indole ring, to generate an intermediate leading to NAS-B. This is accompanied by a low probability event, where the dihedral angle is negative to allow for the formation of an intermediate leading to NAS-C. The sign distribution of the dihedral angle is supported by the product profile of the A86K-V288P double mutant.

\section{Discussion}

Cytochrome P450 (CYP) enzymes are among the most exquisite and versatile biocatalysts in nature to synthesize and modify natural products ${ }^{18,19}$. P450s and their engineered variants are continuously exploited as biocatalysts to functionalize natural products or potential drug leads ${ }^{20}$. P450-catalyzed reactions can be broadly categorized into two groups: common and unusual ${ }^{21}$. Common P450 reactions generate minor structural alterations, such as $\mathrm{C}-\mathrm{H}, \mathrm{N}-\mathrm{H}$ hydroxylation, and epoxidation on $\mathrm{C}=\mathrm{C}$ double bonds. The mechanisms for those reactions are clear and represented by a canonical P450 catalytic cycle while the mechanisms for unusual P450 reactions are often unknown or elusive. Along with uncharacterizedmechanism for uncharted chemistry, unusual P450 reactions may catalyze an enigmatic and/or dramatic structural transformation. Those features of unusual P450 reaction are of special research interests. 
As an unusual P450-catalyzed reaction, the reaction of $\mathrm{NascB}$ was assumed to involve radical generation at $\mathrm{N} 1$ and migration, intramolecular Mannich reaction to form the pyrroloindoline C3 radical, and radical addition to the other molecule of DKP to form the HTDKP framework ${ }^{6}$. Although our previous DFT calculations and experiments preferred the N1-initiation over N10initiation mechanism ${ }^{6}$, there was a lack of direct proof. Based on the crystal structures, we can now clearly see that the $\mathrm{N} 1$ of $\mathrm{cW}_{\mathrm{L}^{-}}$ $\mathrm{P}_{\mathrm{L}}-\mathrm{U}$ is indeed much closer than the N10 to the heme-ligating water molecule (Fig. 3b). In addition, the $c^{2} W_{L}-P_{L}-U$ is in a Ushaped, folded conformation. Its indole and prolyl entities are close to each other, providing a viable distance for the intramolecular Mannich reaction to form the pyrroloindoline C3 radical. As $\mathrm{Nas}_{\mathrm{F} 5053}$ shows no structural evidence to accommodate the second copy of the pyrroloindoline $\mathrm{C} 3$ radical, the radical dimerization mechanism proposed in fungal TDKP biosynthesis can also be excluded ${ }^{7,8}$. Furthermore, the three well superimposed complex structures (Fig. 3c) suggest a conserved starting conformation and reaction initiation steps in the formation of ASPA, NAS-C, and NAS-B, although differentiating conformational dynamics of substrates develop in wild-type $\mathrm{Nas}_{\mathrm{F} 5053}$ and the three mutants, leading to the formation of different products. Therefore, all our structural evidence solidly supports the assumed reaction mode of HTDKPs ${ }^{6}$. Except for the type V HTDKP formation through a N1-radical addition, the intramolecular and intermolecular radical cascade mechanism ${ }^{6}$ thus can be rationalized to be a common paradigm for the biosynthesis of other bacterial HTDKPs.

Our dynamics simulation analyses indicate that the stereospecificity and regio-specificity of P450 is indeed controlled by a sophisticated interaction of the substrates with the protein. This observation is consistent with the previous results for NascB, which can generate various HTDKP products with type I-IV frameworks upon feeding different substrates ${ }^{6}$. In contrast to the substrate-based approach, engineering the specificity conferringresidues is more appealing for biocatalysis to generate structural diversity of HTDKPs. Although the outcome of the reaction specificity cannot be readily predicted solely based on the crystal structures, the identified four specificity-conferring residues can serve as targets for protein engineering. Through screening a small library of mutations on the four residues, the product specificity of $\mathrm{Nas}_{\mathrm{F} 5053}$ was able to be shifted between different frameworks, which enables $\mathrm{Nas}_{\mathrm{F} 5053}$ to predominantly produce NAS-B, NAS-C, ASPA, or even NAS-E. This approach makes it very convenient for biocatalysis to efficiently produce the desired types of HTDKPs. In addition to the five identified types of HTDKPs, engineering the specificity-conferring residues also has the potential to generate diverse frameworks; screening more mutants for finding different specificities is currently in progress.

Besides the regio-specificity and stereo-specificity to generate frameworks, the limited tolerance of P450s for substrates is another factor that restricts their application. Previously, we found $\mathrm{NascB}$ has a very limited freedom in accepting substrates at the $c W_{L}-P_{L}-E$ site ${ }^{6}$. From the structure, $c W_{L}-P_{L}-E$ is surrounded by the bulky residues E73, F387, and L77; especially E73 is very close to the substrate. These residues, constituting the "ceiling" of the pocket, may form a constraint that hinders accepting bulkier substrates. In the P450 dimerases for a few of HTDKP-like products, which contain heterodimerized nucleobase-DKP frameworks $^{22-24}$, E73 is replaced by the larger residue Tyr in GutD and $\mathrm{P}_{450} \mathrm{NB}_{5737}{ }^{22,23}$. As nucleobases are smaller than DKPs, this bulky residue may act as a gatekeeper, to restrict the second copy of DKP entering the pocket and to force the enzyme to catalyze a hetero-dimerization between the nucleobase and DKP. Therefore, engineering these residues may be able to control the space of the binding pocket and subsequently enable the enzymes to accept either larger or smaller substrates in the prolinyl position of $\mathrm{cW}_{\mathrm{L}^{-}}$ $\mathrm{P}_{\mathrm{L}}-\mathrm{E}$, and currently such attempts are in progress. At the bottom of the binding pocket, the U-shaped molecule has more freedom as observed in our previous study ${ }^{6}$, by extending its proline moiety to the tunnel entrance lined by another two gatekeeper residues, V236 and L77. Engineering these two residues has the potential for further broadening of the substrate scope in the "bottom" cavity. By combining the engineering in reaction specificity and pocket space, the $\mathrm{P} 450$ reactions are believed to be able to generate more varied molecular diversity of HTDKPs.

The reaction specificities of $\mathrm{P} 450 \mathrm{~s}$ are determined by the sophisticated and orchestrated enzymatic environments and therefore it is difficult to identify the specificity-conferring residues solely from the crystal structures, especially for Ala86, which is $\sim 6 \AA$ away from $c W_{L}-P_{L}-U$ (Fig. 3b). Through repeated construction and evaluation of sequence chimeras, we provided a strategy to decipher the sequence-product relationships of HTDKP-producing P450 enzymes. This approach proves to be effective in identifying pivotal residues governing product specificity between two or more homologous proteins. Based on these discoveries, we were able to alter the P450s' specificity through protein engineering. For enzymatic reactions with complicated catalytic mechanisms, relying solely on structural analysis can easily miss important information. Therefore, it is better to incorporate the investigation of the sequence-product relationships and our approach provides an option for this purpose.

In conclusion, through discovery, identification, and functional characterization, we have identified a suite of P450s (NasbB, $\mathrm{Nas}_{\mathrm{F5053}}$, and $\mathrm{Nas}_{\mathrm{S1868}}$ ) that share high sequence similarities but generate unique overlapping product profiles across all the five types of bacterial dimeric DKP frameworks. Our systematic mutagenesis studies on the promiscuous $\mathrm{Nas}_{\mathrm{F} 5053}$ and the versatile NascB identified four key resides, Q65, A86, S284, and V288, which play critical roles in controlling product regioconfigurations and stereo-configurations. We demonstrate that the engineering of these residues is able to alter the product ratio and even generate an interesting framework, which has not previously been observed for the substrate $c W_{L}-P_{L}$. To obtain insights into the structural basis for regio-specificity, stereo-specificity, and chemical versatility, we further determined highresolution crystal structures of wild-type $\mathrm{Nas}_{\mathrm{F} 5053}$ in its substratefree and substrate-bound form, and of two Nas $\mathrm{F}_{5053}$ mutants (Q65I-A86G and S284A-V288A) in their substrate-bound forms. The binding mode of $\mathrm{cW}_{\mathrm{L}}-\mathrm{P}_{\mathrm{L}}$ revealed by the complex structures supports the previous proposed intramolecular and intermolecular radical cascade addition mechanism. Molecular dynamics simulations were employed to uncover the specificityconferring mechanism of these residues, based on the crystal structures. Therefore, our biochemical, structural, and computational characterizations across this representative group of HTDKP-forming P450s provide a clear mechanism of how these sophisticated catalytic mechanisms take place, which expands our knowledge on the chemical diversity of cytochrome P450scatalyzed natural products and enables the rational engineering of this group of P450s and other homologs to obtain different HTDKP frameworks.

While this manuscript was undergoing revision after review, Shende and Co-workers published the structural and functional characterization of $\mathrm{NzeB}^{17}$, the synonym of $\mathrm{Nas}_{\mathrm{F5053}}$. Their structural data are consistent with our data. The active site residues that they identified are also covered by four key residues revealed in our manuscript.

\section{Methods}

Protein expression, purification, and enzyme assay. P450 genes with codon optimized for E. coli were cloned into pET28a $\left(\right.$ nas $\left._{F 5053}\right)$ and pMS1 (nasbB and 
$n a s_{S 1868}$ ), which were overexpressed in E. coli BL21 (DE3) and M. smegmatis mc $^{2}$ 155, respectively (Supplementary Fig. 15). The in vitro biochemical reactions using all the P450s mentioned in this study were performed in a $100 \mu \mathrm{L}$ reaction system containg $0.1 \mu \mathrm{M}$ P450, $1 \mathrm{mM} \mathrm{cW}_{\mathrm{L}}-\mathrm{P}_{\mathrm{L}}, 1 \mu \mathrm{M}$ spinach ferredoxin (Fd), $1 \mu \mathrm{M}$ ferredoxin reductase (FdR), $2 \mathrm{mM} \mathrm{NADP}{ }^{+}, 2 \mathrm{mM}$ glucose, and $2 \mathrm{mM}$ glucose dehydrogenase $(\mathrm{GDH})$ in $50 \mathrm{mM}$ HEPES buffer, $100 \mathrm{mM} \mathrm{NaCl}$, at $\mathrm{pH}$ 7.5. After incubating at $4{ }^{\circ} \mathrm{C}$ for $24 \mathrm{~h}$, the reactions were quenched and extracted with ethyl acetate $(2 \times 200 \mu \mathrm{L})$. Then the combined organics were concentrated in vacuo, which were re-dissolved in HPLC-graded methanol and the resulting solutions were filtered through $0.45 \mu \mathrm{M}$ membrane and finally analyed by UHPLC-MS. A Diamonsil (C18, $2 \mu \mathrm{m}, 2.1 \times 50 \mathrm{~mm}$, Shim-pack GIST) was used with a flow rate at $0.3 \mathrm{~mL} \mathrm{~min}^{-1}$ and a PDA detector over a $23 \mathrm{~min}$ gradient program with water (eluent A) and methanol (eluent B): $T=0 \mathrm{~min}, 40 \% \mathrm{~B} ; T=10 \mathrm{~min}, 40 \% \mathrm{~B} ; \mathrm{T}=15$ $\min , 70 \% \mathrm{~B} ; T=18 \mathrm{~min}, 40 \% \mathrm{~B} ; T=23 \mathrm{~min}, 40 \% \mathrm{~B}$.

\section{Protein crystallization and crystal structure determination. Initial crystals} were obtained in $0.2 \mathrm{M} \mathrm{CaCl}_{2}, 20 \%$ (w/v) polyethylene glycol (PEG) 3350, pH 7.5 at $20{ }^{\circ} \mathrm{C}$ using the hanging drop vapor diffusion technique with the addition of $5 \%$ glycerol to the protein stock. The initial crystals were subsequently crushed for seeding by using the Seed Bead Kit (Hampton Research). Final crystals were obtained using the micro-seeding technique in $0.2 \mathrm{M} \mathrm{CaCl}_{2}$, and $22 \%$ (w/v) PEG $3350, \mathrm{pH} 7.5$ at $4{ }^{\circ} \mathrm{C}$. Substrate-bound protein crystals were obtained by soaking the substrate-free crystals in the mother liquor containing $2.5 \mathrm{mM} \mathrm{cW} \mathrm{L}_{\mathrm{L}}-\mathrm{P}_{\mathrm{L}}$ (diluting from $50 \mathrm{mM}$ stock solution in DMSO) for $24 \mathrm{~h}$ or co-crystallization after mixing $0.13 \mathrm{mM}$ protein with $2.5 \mathrm{mM} \mathrm{cW} \mathrm{L}_{\mathrm{L}}-\mathrm{P}_{\mathrm{L}}$. Both methods produce identical complex structures. The complex structure from soaking was chosen for structural analysis and presentation, due to a better overall quality, including resolution, of the diffraction data collected from the soaked crystals.

Crystals were mounted onto CryoLoops (Hampton Research) and soaked in a cryoprotection solution containing $0.2 \mathrm{M} \mathrm{CaCl}_{2}, 22 \%$ (w/v) PEG 3350, pH 7.5, and $20 \%(\mathrm{v} / \mathrm{v})$ glycerol prior to flash freezing in liquid. For the substrate-bound protein crystals, the cryoprotection solution also contained $2.5 \mathrm{mM} \mathrm{cW} \mathrm{L}_{\mathrm{L}}-\mathrm{P}_{\mathrm{L}}$. The X-ray diffraction data were collected at the Australian Synchrotron MX beamlines. The collected data were indexed and integrated using $X^{25}$ and scaled and merged using Aimless ${ }^{26}$. A partial initial model of the holo-structure was obtained by the molecular replacement technique with Phaser in Phenix ${ }^{27}$ using the crystal structure of CYP121 from Mycobacterium tuberculosis (PDB accession code: 5WP2) as the search model. The initial model was improved by using the Morph Model tool in Phenix ${ }^{28}$ and manually modified in COOT $^{29}$. The substrate-bound structure was solved by the molecular replacement technique using the holostructure as the search model. The structures were refined using Phenix.Refine ${ }^{30}$ and manually modified in COOT iteratively. The graphic presentations of protein structures were prepared with Pymol.

NMR spectroscopy. The NMR spectra were recorded on a Bruker Avance III spectrometer at a ${ }^{1} \mathrm{H}$ frequency of $400 \mathrm{MHz}$. Lyophilized samples (varying from 1 to $7 \mathrm{mg}$ ) were dissolved in $280 \mu \mathrm{L}$ DMSO- $d 6$ (Cambridge Isotope) and all spectra were recorded at $25^{\circ} \mathrm{C}(298 \mathrm{~K}) .{ }^{1} \mathrm{H}$ and ${ }^{13} \mathrm{C}$ resonances were assigned through the analysis of $1 \mathrm{D}^{-1} \mathrm{H}, 1 \mathrm{D}{ }^{13} \mathrm{C}, 2 \mathrm{D}{ }^{1} \mathrm{H}-{ }^{1} \mathrm{H}$ ROESY, 2D ${ }^{1} \mathrm{H}-{ }^{13} \mathrm{C} \mathrm{HSQC}$, and $2 \mathrm{D}{ }^{1} \mathrm{H}-$ ${ }^{13} \mathrm{C} \mathrm{HMBC}$ (optimized for long-range heteronuclear couplings of $6 \mathrm{~Hz}$ ). ${ }^{1} \mathrm{H}$ and ${ }^{13} \mathrm{C}$ chemical shifts were calibrated with reference to the DMSO solvent signal (2.50 and $39.5 \mathrm{ppm}$ for ${ }^{1} \mathrm{H}$ and ${ }^{13} \mathrm{C}$, respectively). NMR experiments were processed with Bruker Topspin program (version 3.57) and analyzed with MestReNova software.

Reporting summary. Further information on research design is available in the Nature Research Reporting Summary linked to this article.

\section{Data availability}

The sequences of the $n a s b B, n a s_{S 1868}$, and $n a s_{F 5053}$ reported in this work are available under existent accession numbers MW196742 (this hyperlink is currently on hold and will be released upon publication), WP_030881046.1 and WP_030888003.1 in Genebank, respectively. Their synthetic DNA sequences are listed in the supplementary information. All other data are also available upon request from the corresponding authors. The pdb coordination files for substrate-free F5053 and F5053 in complex with $\mathrm{cW}_{\mathrm{L}}-\mathrm{P}_{\mathrm{L}}, \mathrm{Nas}_{\mathrm{F} 5053^{-}}$ Q65I-A86G in complex with $\mathrm{cW}_{\mathrm{L}}-\mathrm{P}_{\mathrm{L}}$ and $\mathrm{Nas}_{\mathrm{F} 5053}-\mathrm{S} 284 \mathrm{~A}-\mathrm{V} 288 \mathrm{~A}$ in complex with $\mathrm{cW}_{\mathrm{L}^{-}}$ $\mathrm{P}_{\mathrm{L}}$ were deposited in Protein Data Bank with the accession number of 6W0S, 6VXV, $6 \mathrm{VZA}$, and $6 \mathrm{VZB}$, respectively. Source data are provided with this paper.

Received: 19 June 2020; Accepted: 3 November 2020;

Published online: 07 December 2020

\section{References}

1. Borthwick, A. D. 2,5-Diketopiperazines: synthesis, reactions, medicinal chemistry, and bioactive natural products. Chem. Rev. 112, 3641-3716 (2012).
2. Ruiz-Sanchis, P., Savina, S. A., Albericio, F. \& Alvarez, M. Structure, bioactivity and synthesis of natural products with hexahydropyrrolo[2,3-b] indole. Chem. Eur. J. 17, 1388-1408 (2011).

3. Ma, Y.-M., Liang, X.-A., Kong, Y. \& Jia, B. Structural diversity and biological activities of indole diketopiperazine alkaloids from fungi. J. Agric. Food Chem. 64, 6659-6671 (2016).

4. Raju, R. et al. and B: a new dimeric diketopiperazine framework from a marinederived actinomycete, Streptomyces sp. Org. Lett. 11, 3862-3865 (2009).

5. Buedenbender, L. et al. Naseseazine C, a new anti-plasmodial dimeric diketopiperazine from a marine sediment derived Streptomyces $\mathrm{sp}$. Tetrahedron Lett. 57, 5893-5895 (2016).

6. Tian, W. et al. Efficient biosynthesis of heterodimeric C-3-aryl pyrroloindoline alkaloids. Nat. Commun. 9, 4428 (2018).

7. Kishimoto, S., Sato, M., Tsunematsu, Y. \& Watanabe, K. Evaluation of biosynthetic pathway and engineered biosynthesis of alkaloids. Molecules 21, 1078 (2016).

8. Saruwatari, T. et al. Cytochrome P450 as dimerization catalyst in diketopiperazine alkaloid biosynthesis. ChemBioChem 15, 656-659 (2014).

9. Kim, J. \& Movassaghi, M. Concise total synthesis and stereochemical revision of $(+)$-naseseazines A and B: regioselective arylative dimerization of diketopiperazine alkaloids. J. Am. Chem. Soc. 133, 14940-14943 (2011).

10. Cai, S. et al. Aspergilazine A, a diketopiperazine dimer with a rare N-1 to C-6 linkage, from a marine-derived fungus Aspergillus taichungensis. Tetrahedron Lett. 53, 2615-2617 (2012).

11. Yu, H. \& Li, S.-M. Two cytochrome P450 enzymes from Streptomyces sp. NRRL S-1868 catalyze distinct dimerization of tryptophan-containing cyclodipeptides. Org. Lett. 21, 7094-7098 (2019).

12. Kim, J. \& Movassaghi, M. Biogenetically-inspired total synthesis of epidithiodiketopiperazines and related alkaloids. Acc. Chem. Res. 48, 1159-1171 (2015).

13. Repka, L. M. \& Reisman, S. E. Recent developments in the catalytic, asymmetric construction of pyrroloindolines bearing all-carbon quaternary stereocenters. J. Org. Chem. 78, 12314-12320 (2013).

14. Tadano, S., Sugimachi, Y., Sumimoto, M., Tsukamoto, S. \& Ishikawa, H. Collective synthesis and biological evaluation of tryptophan-based dimeric diketopiperazine alkaloids. Chem. Eur. J. 22, 1277-1291 (2016).

15. Belin, P. et al. Identification and structural basis of the reaction catalyzed by CYP121, an essential cytochrome P450 in Mycobacterium tuberculosis. Proc. Natl Acad. Sci. USA 106, 7426-7431 (2009).

16. Schenkman, J. B. \& Jansson, I. Spectral analyses of cytochromes P450. Methods Mol. Biol. 320, 11-18 (2006).

17. Shende, V. V. et al. Structure and function of $\mathrm{NzeB}$, a versatile $\mathrm{C}-\mathrm{C}$ and $\mathrm{C}-\mathrm{N}$ bond forming diketopiperazine dimerase. J. Am. Chem. Soc. 142, 17413-17424 (2020).

18. Greule, A., Stok, J. E., De Voss, J. J. \& Cryle, M. J. Unrivalled diversity: the many roles and reactions of bacterial cytochromes $\mathrm{P} 450$ in secondary metabolism. Nat. Prod. Rep. 35, 757-791 (2018).

19. Rudolf, J. D., Chang, C. Y., Ma, M. \& Shen, B. Cytochromes P450 for natural product biosynthesis in Streptomyces: sequence, structure, and function. Nat. Prod. Rep. 34, 1141-1172 (2017).

20. Di Nardo, G. \& Gilardi, G. Natural compounds as pharmaceuticals: the key role of cytochromes P450 reactivity. Trends Biochem. Sci. 45, 511-525 (2020).

21. Zhang, X. \& Li, S. Expansion of chemical space for natural products by uncommon P450 reactions. Nat. Prod. Rep. 34, 1061-1089 (2017).

22. Liu, J., Xie, X. \& Li, S.-M. Guanitrypmycin biosynthetic pathways imply cytochrome P450 mediated regio- and stereospecific guaninyl-transfer reactions. Angew. Chem. Int. Ed. 58, 11534-11540 (2019).

23. Yu, H., Xie, X. \& Li, S.-M. Coupling of guanine with cyclo-L-Trp-L-Trp mediated by a cytochrome P450 homologue from Streptomyces purpureus. Org. Lett. 20, 4921-4925 (2018).

24. Shi, J. et al. Genome mining and enzymatic total biosynthesis of purincyclamide. Org. Lett. 21, 6825-6829 (2019).

25. Kabsch, W. Xds. Acta Cryst. D66, 125-132 (2010).

26. Evans, P. R. \& Murshudov, G. N. How good are my data and what is the resolution? Acta Cryst. D69, 1204-1214 (2013).

27. Adams, P. D. et al. PHENIX: a comprehensive Python-based system for macromolecular structure solution. Acta Cryst. D66, 213-221 (2010).

28. Terwilliger, T. C. et al. Model morphing and sequence assignment after molecular replacement. Acta Cryst. D69, 2244-2250 (2013).

29. Emsley, P., Lohkamp, B., Scott, W. G. \& Cowtan, K. Features and development of Coot. Acta Cryst. D66, 486-501 (2010).

30. Afonine, P. V. et al. Towards automated crystallographic structure refinement with phenix.refine. Acta Cryst. D68, 352-367 (2012).

\section{Acknowledgements}

We thank Prof. Rob Capon and Dr. Zeinab Khalil for kindly providing the Streptomyces sp. CMB-MQ030 strain and the NAS-B standard; Prof. Xiaoyong Fan for the gift of the plasmid pMV406; Prof. Jiaoyu Deng for the gift of pMV206 and M. smegmatis mc $^{2}$ 155; Prof. Xiaoyan Cui for providing help in UV-Vis Spectroscopy analysis and Prof. Jeffrey 
R. Harmer for critical discussion in UV-Vis titration. This work was supported in part by the NSFC (31770063 to X.Q.), National Key R\&D Program of China (2018YFC1706200 to X.Q.), Shanghai Post-doctoral Excellence Program (2019193 to C.S.), The University of Queensland (UQ Early Career Researcher Grant UQECR1946973 to X.J.), Australian Research Council (ARC Laureate Fellowship FL180100109 to B.K.). We acknowledge the facilities, and the scientific and technical assistance of the Australian Microscopy and Microanalysis Research Facility at the Centre for Microscopy and Microanalysis, The University of Queensland and the macromolecular crystallography (MX) beamlines at the Australian Synchrotron, Victoria, Australia.

\section{Author contributions}

X.Q., X.J., B.K., and Z.D. conceived this project; C.S., W.Z., W.T., H.P., and Zhi Lin performed the biochemical experiment; Z.L. and X.J. solved the crystal structures; X.Q., X.J., C.S., and Z.L. analyzed data; and X.Q., X.J., C.S., and Z.L. wrote the manuscript.

\section{Competing interests}

The authors declare no competing interests.

\section{Additional information}

Supplementary information is available for this paper at https://doi.org/10.1038/s41467020-20022-5

Correspondence and requests for materials should be addressed to B.K., X.J. or X.Q.
Peer review information Nature Communications thanks Gianfranco Gilardi, Kirsty McLean, and Kenji Watanabe for their contribution to the peer review of this work. Peer review reports are available.

Reprints and permission information is available at http://www.nature.com/reprints

Publisher's note Springer Nature remains neutral with regard to jurisdictional claims in published maps and institutional affiliations.

cc (i) Open Access This article is licensed under a Creative Commons Attribution 4.0 International License, which permits use, sharing, adaptation, distribution and reproduction in any medium or format, as long as you give appropriate credit to the original author(s) and the source, provide a link to the Creative Commons license, and indicate if changes were made. The images or other third party material in this article are included in the article's Creative Commons license, unless indicated otherwise in a credit line to the material. If material is not included in the article's Creative Commons license and your intended use is not permitted by statutory regulation or exceeds the permitted use, you will need to obtain permission directly from the copyright holder. To view a copy of this license, visit http://creativecommons.org/ licenses/by/4.0/.

(C) The Author(s) 2020 